\title{
Identification of Pistachio (Pistacia vera L.) Nuts with Microsatellite Markers
}

\author{
Riaz Ahmad, Louise Ferguson, and Stephen M. Southwick ${ }^{1}$ \\ Department of Pomology, University of California, One Shields Avenue, Davis, CA 95616
}

AdDITIONAL INDEX wORDS. SSR, DNA fingerprinting, genetic markers, product purity

\begin{abstract}
A genomic DNA library enriched for dinucleotide (CT)n and (CA)n and trinucleotide (CTT)n microsatellite motifs has been developed from 'Kerman' pistachio (Pistacia vera $\mathrm{L}$.). The enrichment method based on magnetic or biotin capture of repetitive sequences from restricted genomic DNA revealed an abundance of simple sequence repeats (SSRs) in the pistachio genome which were used for marker development. After an enrichment protocol, about $64 \%$ of the clones contained (CT)n repeats while 59\% contained (CA)n for CT and CA enriched libraries, respectively. In the (CT)n enriched library, compound sequences were $45 \%$ while for (CA)n it was $13.5 \%$. In both dinucleotide enriched libraries, about $80 \%$ of the clones having microsatellites have a repeat length in the range of 10 to 30 units. A library enriched for trinucleotide (CTT)n contained $<19 \%$ of the clones with (CTT)n repeats. Of the clones that contained microsatellites, $62 \%$ had sufficient flanking sequence for primer design. An initial set of 25 pairs of primers was designed, out of which 14 pairs amplified cleanly and produced an easily interpretable PCR product in the commercially important American, Iranian, Turkish, and Syrian pistachio cultivars. The efficient DNA extraction method developed for pistachio kernels and shells (roasted and nonroasted) yielded DNA of sufficient quality to use PCR to create DNA fingerprints. In total, 46 alleles were identified by 14 primer pairs and a dendrogram was constructed on the basis of that information. The SSR markers distinguished most of the tested cultivars from their unique DNA fingerprint. An UPGMA cluster analysis placed most of the Iranian samples in one group while the Syrian samples were the most diverse and did not constitute a single distinct group. The maximum number of cultivar specific markers were found in 'Kerman'(4), the current industry standard in the United States, and the Syrian cultivar Jalab (5). The technique of using extracted DNA from pistachio kernal or shell coupled with the appropriate marker system developed here, can be used for analyses and measurement of trueness to type.
\end{abstract}

Pistachio (Pistacia vera) is a diploid $(2 \mathrm{n}=30, \mathrm{X}=15)$, dioecious wind pollinated tree. Pistacia vera is native of north east Iran, north Afghanistan and middle Asian republics (Zohary and Hopf, 1994). The major pistachio producing countries of the world are, in order, Iran, United States (where all production occurs in California), Turkey and to a lesser extent, Syria, India, Greece, and Pakistan. California's industry relies on a single female cultivar, Kerman, and primarily one male cultivar, Peters (Ferguson, 1998). 'Kerman' was introduced to California from Iran. In other countries several cultivars, and probably their clones, are grown. California has become the second largest pistachio producer in the world, competing with other countries in the international market. Since Executive Order 12613 (1) established an embargo against importations of Iranian product to the United States (Dyszel and Pettit, 1990), there has been concern that Iranian pistachios, falsely labeled as Turkish, are entering the United States domestic market. The ability to conclusively identify pistachio nuts may help to prevent any mix up in the markets.

Patterns of genetic diversity in pistachio have been studied using a variety of morphological, physiological, and biochemical methods (Zohary, 1952). Barone et al. (1993) and Dollo (1993) used isozymes to distinguish pistachio species and cultivars. However, the lack of sufficient isozyme polymorphism among closely related cultivars limited the ability of isozyme markers to distinguish the genetic diversity and relatedness of pistachio cultivars. Karaca and Nizamoglu (1995) tested Turkish and Iranian pistachio nuts on the basis of protein contents and fat percentages,

Received for publication 03 Oct. 2002. Accepted for publication 23 June 2003. The authors wish to thank Bob Klein for providing pistachio samples for DNA analysis in the present project. We are also thankful to Dan Potter and Thomas Chao for critical internal review of the manuscript. We thank the California Pistachio Commission for partial financial support of this project.

1To whom correspondence should be addressed; e-mail smsouthwick@ucdavis.edu. but no significant differences were found that could be used for cultivar identification. In another experiment Agar et al. (1995a) separated Turkish and Iranian pistachio cultivars on the basis of fat content and fatty acid composition, but their distinctions were not sufficient for individual cultivar identification. Dyszel and Pettit (1990) also used fatty acid profiles to determine the country of origin of pistachio nuts by differential scanning calorimetry (DSC) and high-performance liquid chromatography (HPLC). Since the oil was extracted from composite samples this analytical method cannot be used for individual nuts. Furthermore, Agar et al. (1995b) found that fat content and fatty acid composition of the same pistachio cultivar differed significantly in different ecological zones in Turkey.

Molecular markers based on DNA are stable, detectable in all tissues and independent of environmental or seasonal conditions. They can be used for cultivar identification, diversity analysis, assessment of parentage, patent issues and quality control of rootstock-seed lots. One of the most reliable molecular marker systems is microsatellites or simple sequence repeats (SSRs) which are abundant and well distributed throughout the nuclear genomes of eukaryotes. These are mostly present in noncoding DNA, which can accumulate mutations more easily than the coding DNA. Simple sequence length polymorphism (SSLP) caused by variation in the number of repeat units, can be easily detected by PCR using pairs of primers designed from unique sequences bordering the SSR motifs. These markers are highly polymorphic, multiallelic, codominant, and have proven useful for a variety of purposes including fingerprinting (Smith and Devey, 1994), cultivar identification and genetic mapping (Kijas et al., 1997; Guilford et al., 1997), and studying population genetics (Haymer, 1994). Microsatellite loci developed from genomic DNA libraries tend to map randomly throughout the genome and are suitable for comparative genetic studies. The genetic profiles produced 
by multiplexing specific combinations of microsatellite markers can be used in conjunction with pedigree and performance data to document ownership and protect intellectual property rights (McCouch et al., 1997).

Normally, leaves are used for extracting DNA, but leaves may not always be available. The use of pistachio nuts for genotyping purposes, especially in the market place, is of particular interest since access to the tree is not always possible. If nuts could be used for fingerprinting, then samples could be obtained from storage facilities or from supermarkets. Pistachio nuts are rich in lipids, which form a visible layer over the tissue homogenate during normal isolation of DNA, and pose difficulty in recovery and further processing of supernatants. Methods of extracting DNA from nuts (kernel and shell), would help to monitor cultivar identity, protecting plant breeders' rights and maintaining quality control and identity in the market place. This project was designed 1) to establish the presence, abundance and characteristics of the two classes of dinucleotides, (CT/GA)n and (CA/GT)n and trinucleotide (CTT)n microsatellites in the pistachio genome; 2) to develop a DNA extraction method from roasted and nonroasted pistachio kernels and shells; 3 ) to use microsatellite markers to identify pistachio cultivars grown in Iran, Turkey, Syria, and the United States using pistachio kernal or shell DNA extract; and 4) to reveal the identity of pistachios sold in grocery stores.

\section{Material and Methods}

Plant material. In the present study, we collected pistachio nuts from commercially cultivated pistachio cultivars in Iran, ('Fandoghi 48', 'Fandoghi', 'Akbery', 'Kaleh Ghoochi', 'Ohadi', 'Ahmad Aghaii', 'Jandoghii', 'Baddami'), Turkey, ('Siirt a', and 'Siirt b', from different locations), Syria, ('Ashoury', 'Jalab', 'Nab El-Jamal', 'Bundouky', 'Batoury', 'Bayady'), and from the United States ('Kerman'). In addition, nine commercial samples were collected from stores in the United States and in Europe including roasted and nonroasted pistachios.

ISOLATION OF MICROSATELLITE SEQUENCES. An enriched library for (CA)n and (CT)n and (CTT)n repeat motifs was constructed from genomic DNA of pistachio cultivar 'Kerman' following the procedure of Hamilton et al. (1999) with some modifications by Ahmad et al. (2003). In summary, $15 \mu \mathrm{g}$ genomic DNA was digested with Rsa 1 and Nhe 1 restriction enzymes. Fragments at the range of 300 to $800 \mathrm{bp}$ were dephosphorylated and ligated to adopters. Fragments having SSRs were selected by hybridization with biotinilated-oligonucleotides complementary to the repetative sequence $\mathrm{CT} / \mathrm{AG}, \mathrm{CA} / \mathrm{GT}$ and CTT/GAA and recovered by magnetic beads linked to streptavidine. Fragments were amplified by PCR and cloned into the pCR2.1 Topo cloning vector (Invitrogen, Carlsbad, Calif.) and chemically transformed into the Escherichia coli competent cells Top10 (Invitrogen) according to the manufacturer's protocol.

Primer Selection and SSR loci amplification. Colonies having sufficient insert size were transferred to LB kanamycin freezing medium. Plasmids were isolated by plasmid mini kit (Qiagen, Valencia, Calif.). Sequencing was done in ABI 373 Auto Sequencer (Global Medical Instrumentation, Inc., Albertville, Minn.) using M13 (-21) forward primer. In some cases when the insert was long, resequencing was done by using M13 reverse primer. For each unique microsatellite that contained sufficient reliable flanking sequence, PCR primers were selected using the primer selection computer program Primer 3 (Cambridge, Mass.). The forward primers were labeled with IRD800 or IRD700 to be detected on an automated DNA sequencer (Li-Cor, Lincoln, Nebr.). PCR was carried out in a total volume of $12 \mu \mathrm{L}$ under the following conditions: 20 to $25 \mathrm{ng}$ of template DNA, $250 \mathrm{nmol}$ each primer, $200 \mu$ mol dNTPs, 1 unit of Taq Polymerase (Qiagen), 1.5 to $2 \mathrm{~mm} \mathrm{MgCl}_{2} 1 \times \mathrm{PCR}$ buffer. The reaction, depending on the primer pair, was run for 35 to 45 cycles (denaturing at $94{ }^{\circ} \mathrm{C}$ for $1 \mathrm{~min}$, annealing at $55^{\circ} \mathrm{C}$ or $60{ }^{\circ} \mathrm{C}$ for $1 \mathrm{~min}$, with a $2-\mathrm{min}$ extension at $72{ }^{\circ} \mathrm{C}$ ), followed by a single extension at $72{ }^{\circ} \mathrm{C}$ for $60 \mathrm{~min}$. The amplification products were detected on $5.5 \%$ polyacrylamide gels using a DNA sequencer (LI-COR). PCR was performed three times on the same samples and gels were run separately to confirm the observed alleles. Gene Image IR analysis software (Scanalytics, Fairfax, Va.) was used for measuring allele size. Manual editing of the allele size was performed for more accuracy. Bands were scored as present (1) or absent (0). The PAUP 4.0b10 software package (Swofford, 1999) was used to generate a mean character differences matrix and then to produce a dendrogram using the unweighted pair group method based on arithmetic averages (UPGMA).

DNA EXTRACTION FROM NUTS. For pistachio kernels (cotyledons) a 50- to $100-\mathrm{mg}$ sample was put into a $1.5-\mathrm{mL}$ microcentrifuge tube. To that tube $500 \mu \mathrm{L}$ extraction buffer (2\% CTAB, $100 \mathrm{~mm}$ Tris-HCl, pH 8.0, $1.4 \mathrm{M} \mathrm{NaCl}, 20 \mathrm{~mm}$ EDTA, 1\% PVP-40 and $10 \mathrm{~mm}$ DTT) preheated at $65^{\circ} \mathrm{C}$ was added and kept for 10 to 20 min at room temperature so that the cotyledons absorbed some of the extraction buffer. The sample was ground in the buffer with a pestle until a homogeneous mixture was obtained. The uncrushed parts were removed with a pipette tip. Ten microliters proteinase $\mathrm{K}\left(50 \mu \mathrm{g} \cdot \mathrm{mL}^{-1}\right)$ was then added and incubated at $65^{\circ} \mathrm{C}$ for 30 $\mathrm{min}$ in a water bath. The tubes were cooled to room temperature and $500 \mu \mathrm{L} 24$ chloroform : 1 isoamyl alcohol was added. The solution was gently mixed and centrifuged at 9,750 $g_{\mathrm{n}}$ for 10 min. The supernatant was transferred to a new tube, two-thrids volume isopropanol was added and mixed gently to precipitate the DNA. The mixture was centrifuged at 9,750 $g_{\mathrm{n}}$ for $5 \mathrm{~min}$, the supernatant was removed and the DNA pellet was washed with $70 \%$ ethanol. The pellet was air dried and resuspended in $100 \mu \mathrm{L}$ of TE buffer.

In some instances, white particles from nut cotyledons were found with the DNA, which was difficult to distinguish from the DNA. Those particles can be removed by the following procedure. After addition of $100 \mu \mathrm{L}$ TE buffer to the DNA pellet, it was left for several hours at room temperature. The DNA dissolved in the solution while the white particles remained undissolved. The tube was centrifuged at $9,750 \mathrm{~g}_{\mathrm{n}}$ for $5 \mathrm{~min}$. The solution was transferred to a new tube without disturbing the white particles. One tenth volume of $3 \mathrm{~m}$ sodium acetate and two volumes of $100 \%$ ethanol were added, mixed gently and kept at $-20^{\circ} \mathrm{C}$ for $30 \mathrm{~min}$. Following centrifugation at $9,750 g_{\mathrm{n}}$ for $15 \mathrm{~min}$, the supernatant was removed and the pellet was washed with $70 \%$ ethanol, air dried and resuspended in $50 \mu \mathrm{L}$ TE buffer.

The same procedure was followed for DNA extraction from the pistachio nut shell except that shells were ground to powder in liquid nitrogen by an electric grinder or by pestle. About 20 to $40 \mathrm{mg}$ of powder were used for DNA extraction with initial incubation at $65^{\circ} \mathrm{C}$ for 3 to $6 \mathrm{~h}$. DNA cleaning was also not performed in this case.

We also used the DNeasy plant mini kit (Qiagen) for DNA extraction from pistachio kernels and shell following the manufacturer's protocol. DNA quality and quantity was measured with ethidium bromide-stained $1 \%$ agarose gel and the $\mathrm{A}_{260}: \mathrm{A}_{280}$ ratio was determined using UV-2401 spectrophotometer (Shimadzu 
Scientific Instrument, Inc., Pleasanton, Calif.). Extracted DNA from all methods were diluted to $10 \mathrm{ng} \cdot \mu \mathrm{L}^{-1}$ and $2 \mu \mathrm{L}$ were used for PCR amplification in a total volume of $12 \mu \mathrm{L}$.

\section{Results and Discussion}

LIBRARY SCREENING AND SEQUENCE CHARACTERIZATION. After sequencing 89 clones randomly selected from a total of 295 clones for (CT/GA)n enriched library, 57 (64\%) contained microsatellites of which $26(45 \%)$ were compound. From a (CA/GT)n enriched library, 62 clones, randomly selected from a total of 250 clones, were sequenced, 37 (59\%) contained microsatellites of which five (13.5\%) were compound. The compound sequences consisted of classes of di, tri, and tetra-nucleotide repeats alternating with (CT)n and (CA)n repeats. Eight $(8.9 \%)$ and five $(8.1 \%)$ clones were redundant in the $(\mathrm{CT} / \mathrm{GA}) \mathrm{n}$ and $(\mathrm{CA} / \mathrm{GT}) \mathrm{n}$ libraries, respectively. In the (CT/GA)n enriched library, $75 \%$ of the clones having a microsatellite had repeat length in the range of 10 to 30 units while $19.2 \%$ had repeat length in the range of 30 to 50 units and $5.8 \%$ had more than 50 repeat units. For the $(\mathrm{CA} / \mathrm{GT})$ n library, $82 \%$ of the clones having a microsatellite contained repeat length at 10 to $30 \mathrm{bp}$ while the remaining $18 \%$ had 30 to 50 bp length. Of the total 151 clones having a dinucleotide microsatellite, 67 (44\%) had sufficient flanking sequence for primer design. From a library enriched for trinucleotide repeats (CTT/GAA)n, we randomly selected 33 clones for sequencing from a total of 175 clones. Eight $(24 \%)$ clones have the trinucleotide microsatellite with sufficient flanking sequence for primer design. The rest of the clones were discarded because they either had no microsatellite, the microsatellite was too small, or the microsatellite was too close to the cloning site to allow for flanking sequence primer design. An initial set of 25 pairs of primers were designed and tested. Of these, 14 pairs amplified very clean and easily interpretable PCR products, while the rest did not amplify any product or resulted in a smear of bands that could not be interpreted.

From the present results, it was observed that the enrichment protocol could be efficiently used for finding clones having microsatellites. We found on average $61.5 \%$ of the clones contained a SSR. According to Thomas et al. (1998), $21 \%$ of clones from an enriched library developed in grapevine contained microsatellite sequences. Butcher et al. (2000) observed, after an enrichment procedure, that $40 \%$ of colonies contained microsatellites. The Kijas et al. (1997) method involves the construction of genomic libraries before the enrichment step and is therefore likely to be more time consuming.

Our results indicated that trinucleotide copy number in the pistachio genome is lower than that of the dinucleotide repeats as observed by Thomas et al. (1998) and Kijas et al. (1995) in citrus and Guilford et al. (1997) in apple.

It was observed that sufficient microsatellite-containing sequences are available in the pistachio genome for marker development. Our enrichment procedure captured more CT repeats than CArepeats. Surveys in plants have shown that the most frequently occurring dinucleotide repeats are (AT)n with (CT)n and (CA)n as second and third most frequent (Powell et al., 1996; Wang et al., 1994). In pistachio, the most common motif (CT)n had more compound microsatellites than (CA)n.

ISOLATION AND PURITY OF DNA FROM NUTS. DNA extraction was assayed for 50, 100, 200, 300, and $400 \mathrm{mg}$ of pistachio kernel while for shell it was $\approx 20,40,60,80$, and $100 \mathrm{mg}$ powder.

Table 1. Primer sequences, repeat motifs, number of putative alleles and their size range revealed by 14 microsatellite in pistachio cultivars.

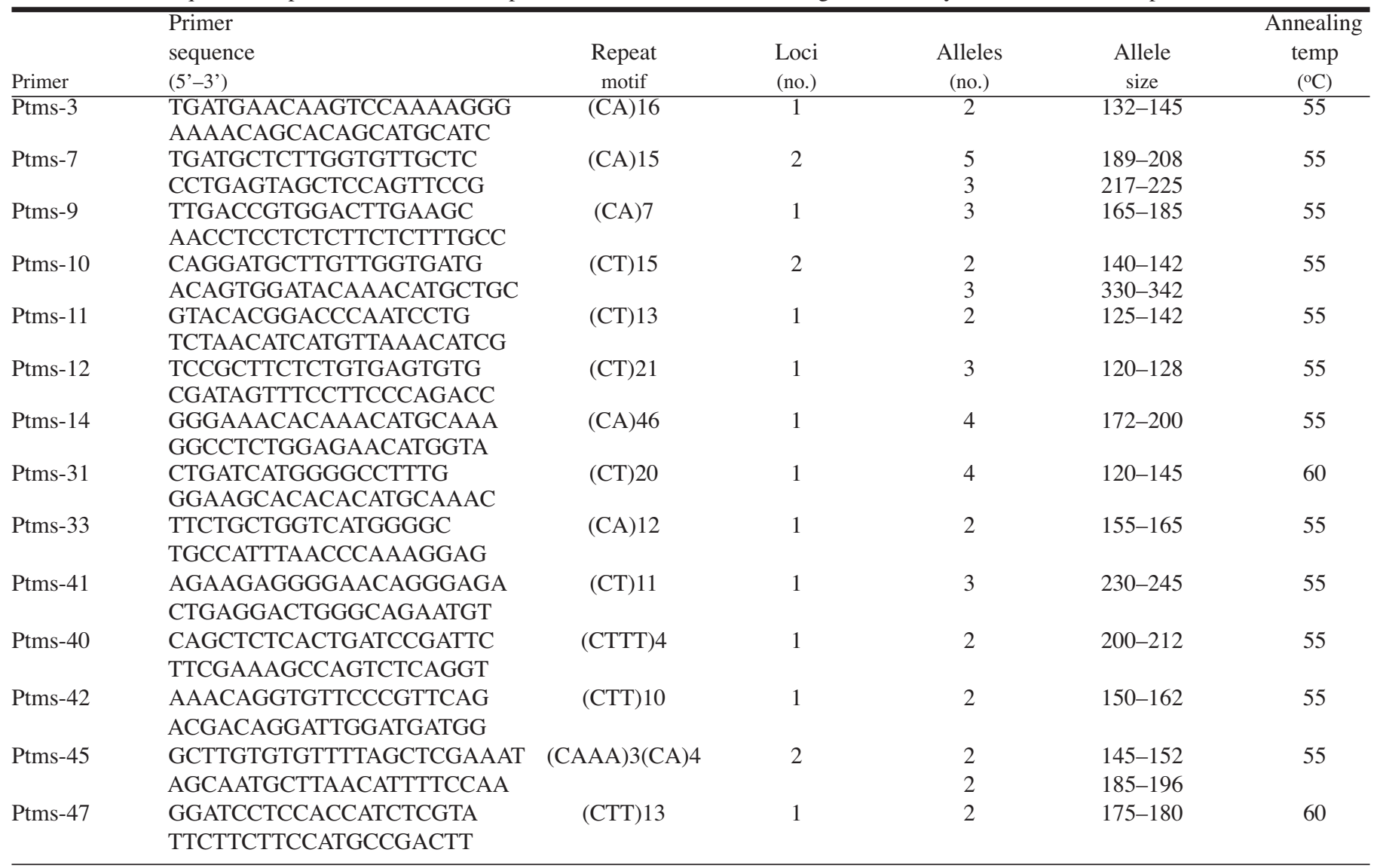




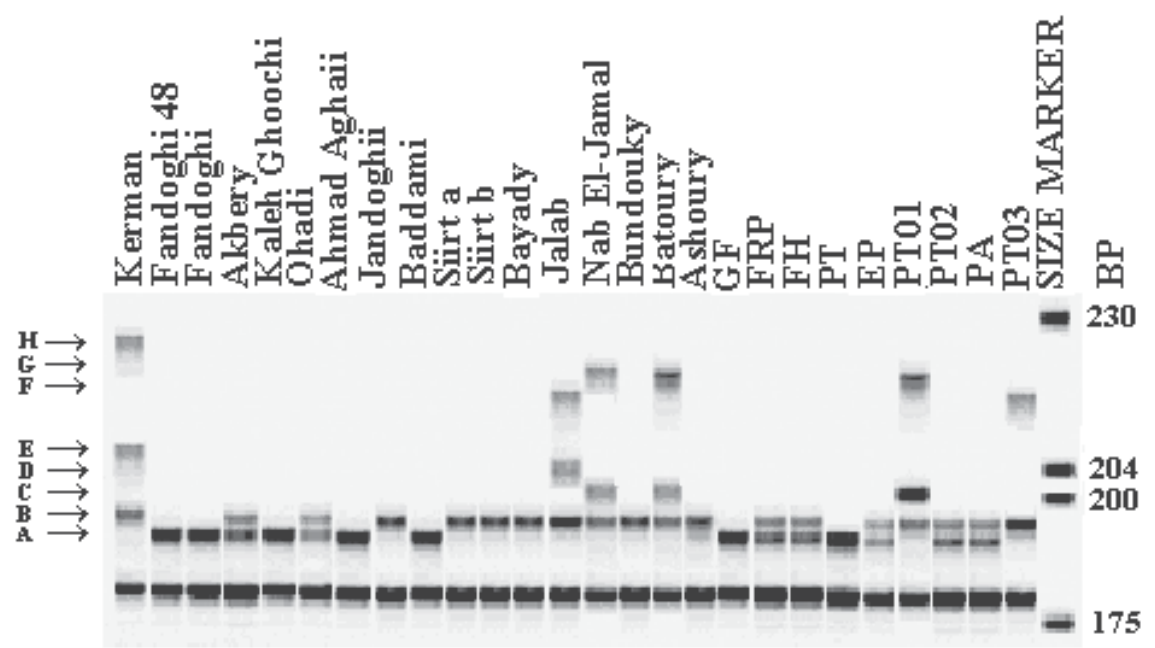

Ptus-7

Fig. 1. Amplification product of microsatellite locus Ptms-7 in 17 pistachio cultivars and 9 pistachio samples (GF, FRP, FH, PT, EP, PT01, PT02, PA, PT03) collected from the market. DNA was extracted from either kernel or shell. Five alleles (A-E) for the first putative locus and three alleles $(\mathbf{F}-\mathbf{H})$ for the second putative locus have been indicated at left side of the gel. The IRD-labled size marker (LI-COR) at the right side was used for measuring allele size.

The amount of the tissue processed is an important factor. DNA yield was optimal when 50 and $100 \mathrm{mg}$ of kernel tissue were processed. Most of the extraction buffer solution is absorbed by the cotyledon when the processed tissue was increased further resulting in lowering the DNA concentration. In total, $\approx 7.5 \mu \mathrm{g}$ of DNA was obtained from $100 \mathrm{mg}$ of unroasted kernel tissue while in the case of roasted nuts, DNA from kernels was mostly degraded and after testing three times separately was found not to be suitable for PCR reaction. The degradation of DNA is probably due to the high temperature during processing of nuts, which distorts the cells, nuclei, and ultimately the genomic material. DNA extracted from the unroasted kernel appeared to be of high molecular weight with little shearing and easy mobility with the $\mathrm{A}_{260}: \mathrm{A}_{280}$ ratio in the range of 1.79 to 1.85 . No liquid nitrogen was used in the extraction of DNA from kernel tissue. The tissue was softened by the uptake of the buffer solution. More than 100 samples can be processed by a single person in one day because of the easy grinding procedure.

Twenty to forty milligrams of ground powder from shell resulted in 2 to $2.5 \mu \mathrm{g}$ of DNA. The fibrous, hard shell tissue was loosened with an electric grinder or pestle under liquid nitrogen. Due to the grinding procedure 20 to 30 samples can be handled by a single person in one day, but DNA from both roasted and unroasted nut shells was of pure quality and suitable for downstream application which is a clear advantage over the roasted kernel DNA. Lipid content, which may hinder subsequent fingerprinting by making the samples hydrophobic, is low in shells. Quality of the DNA was verified with $\mathrm{A}_{260}: \mathrm{A}_{280}$ ratio which was in the range of 1.78 to 1.81 and consistent amplification in the PCR for 14 SSR marker analyses.

The quality and quantity of the DNA extracted from nut shells by our protocol and that of the plant DNeasy kit (Qiagen) were equivalent. For that from kernels, the Qiagen kit was a better alternative because more of the white particles from the cotyledons are removed by the filter. Extraction of DNA from kernels and shells is the only alternative when access to the original trees is not possible. Also, the maternal origin of the nutshell, reflects the genetic constitution of the female parent. That makes it easy to compare the California pistachio 'Kerman' with those of foreign origin, since generally the male parents of the foreign pistachio are unknown.

Marker evaluation. The 14 microsatellite-specific primer pairs which resulted in a clear PCR product and amplified the expected target in pistachio 'Kerman' were further tested for their efficiency in detecting polymorphism among 17 pistachio cultivars from different origins and nine other samples collected from the market. Primer sequences, repeat motif, number of alleles and their expected size range are shown in Table 1. Eleven primer pairs produced single locus PCR fragments of one or two bands while three resulted in reproducible complex patterns of several bands. No significant difference in polymorphism between CA-GT and CT-GA microsatellites was found. No correlation between the number of repeats of a microsatellite and the number of alleles detected within the tested pistachio cultivars was observed.

All primers revealed polymorphisms except Ptms-11. A total of 46 alleles were detected with an average of 3.3 alleles per primer combination. All microsatellite loci that amplified in the tested pistachio samples displayed between 2 to 5 putative alleles for each locus. Figure 1 shows an example in which the DNA from pistachio cultivars was amplified by the primer combination Ptms-7 to display the complex banding pattern. Since pistachio is of diploid origin with $2 \mathrm{n}=30$ and $\mathrm{X}=15$ (Fasihi-Harandi et al., 2001), there is no possibility of tetraploidy. The complex banding pattern can be explained only by assigning second locus to the amplification product. In some cases, a monomorphic locus at the upper or lower part of the gel appeared which is common in microsatellite analyses, e.g., the common band at 180 base pair (bp), which is present in all cultivars, is a monomorphic locus amplified by the microsatellite Ptms-7 (Fig. 1) and was not taken into the actual allele count. The first locus identified five alleles (A-E) that distinguished the two cultivars Kerman and Jalab from the rest of the cultivars due to their unique fingerprint. The putative alleles (E) at 208 bp for 'Kerman' cannot be seen in other cultivars. Similarly, the putative alleles (D) at $206 \mathrm{bp}$ are specific for 'Jalab', which uniquely identified this cultivar from the rest of the cultivars. The amplification product produced by Ptms-7 in some cultivars at 217 to $225 \mathrm{bp}$ were assigned a second putative locus since it did not amplify at the expected size which is $193 \mathrm{bp}$ for Ptms-7. Three alleles $(\mathrm{F}, \mathrm{G}, \mathrm{H})$ were identified by this putative locus in the pistachio samples. The second locus may be the result of duplication in some cultivars which can only be confirmed by segregating analyses and mapping of the locus on the chromosome or by sequencing both loci. According to Temnykh et al. (2001), out of 200 SSRs in rice, 12 amplified complex patterns of several independently segregating bands, which in some cases were mapped at multiple loci. McCouch et al. (1997), also found that five out of the 120 SSR markers appeared to be multiple copies, half of which were found to reside in duplicated regions of the rice genome. We confirmed the results of each locus when gels were run three times separately with the same SSR marker and with different dilutions of the PCR product. We also increased the annealing temperature from 55 to $60{ }^{\circ} \mathrm{C}$ for each microsatellite to remove the possibility of any spurious 


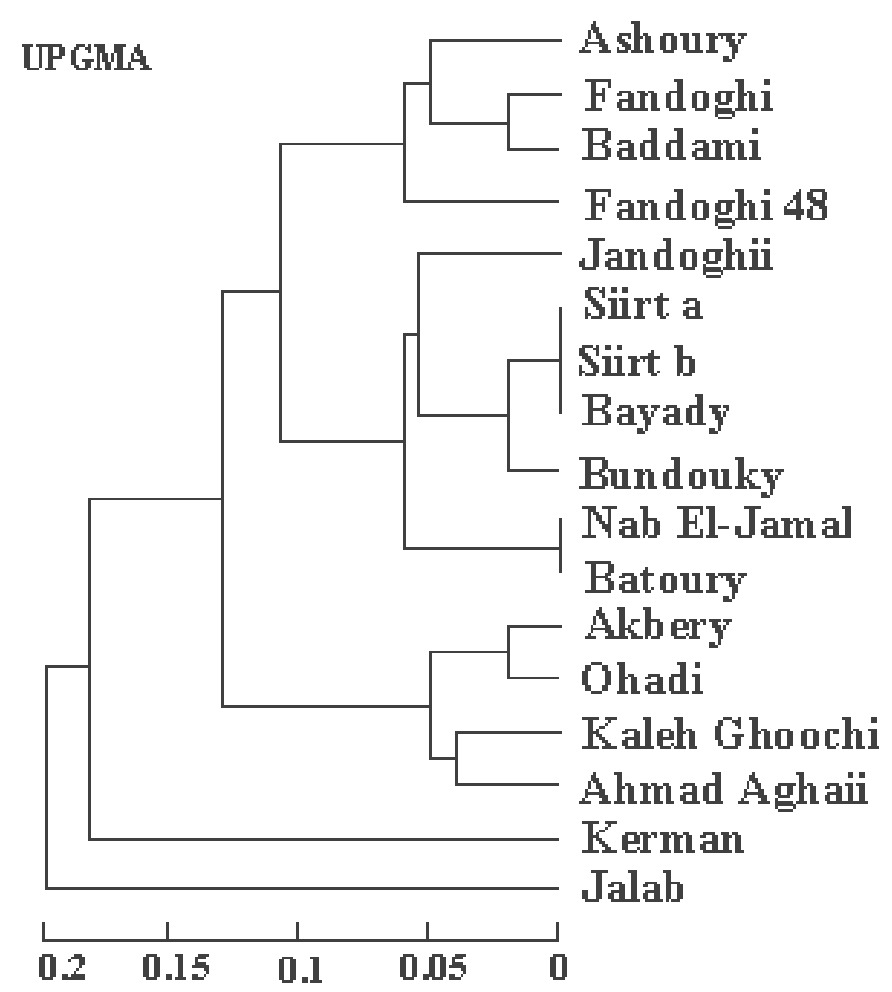

Fig. 2. Dendrogram of 17 pistachio cultivars produced by unweighted pair group method average (UPGMA) cluster analysis using the matrix of mean character differences.

bands, but the results were consistent.

All pistachio nut samples collected from the market except PT03 were identified by comparing DNA fingerprint of each sample one by one with the DNA fingerprints generated by the 14 SSR markers in the standard commercial cultivars. To confirm the identity of pistachio sample PT03, more commercial cultivars and more SSR markers could be included in future analyses.

The relationship among the 17 pistachio cultivars included in this study is represented by the UPGMA dendrogram. In this dendogram, Iranian samples ('Akbery', 'Ohadi', 'Kaleh Goochi', 'Ahmad Aghaii') grouped in one cluster (Fig. 2), which is distant from the other three Iranian samples 'Fandoghi', 'Fandoghi-48' and 'Baddami'. These three Iranian samples grouped with the Syrian cultivar 'Ashoury'. 'Fandoghii', 'Baddami', 'Kaleh Goochi', and 'Jandoghii', were identified by one cultivar specific allele (allele present in only one cultivar, but not in others). The United States commercial cultivar Kerman was close to the Iranian cultivars, but did not group with those. The DNA fingerprint of 'Kerman' was very distinct from the fingerprint of other cultivars. Four cultivar-specific putative alleles were found for 'Kerman'.

According to FAO statistics, Syria is classified as the fourth pistachio producing country in the world, but classification and identification of pistachio cultivars in Syria are very rare. Al-Husny (1972) published some characteristics of Syrian female varieties. Nahlawi et al. (1985), presented results of five varieties in a comparative study, namely 'Ashoury', 'Batoury', 'Oleimy', 'Bundouky', and 'Ain El-Thainah'. In our results, Syrian pistachios were very diverse and did not group into one cluster. No marker was found to separate two Syrian pistachio cultivars Nab El-Jamal and Batoury. Cultivar Jalab is distinct from the rest of the pistachio samples by giving the maximum number of five cultivar specific markers. According to Hormaza et al. (1994), the Syrian pistachio was not obtained from ancient Iranian germplasm, but, had a local origin. The only evidence to support this hypothesis is the reported findings of pistachio nuts from excavations on Neolithic settlements in Syria (Bender, 1975; Kramer, 1982). Contrary to the previous results, our result showed a wider genetic base for Syrian samples than for Iranian samples. This result might change if more samples from these two regions are analyzed with more SSR markers.

In Turkey, during the last decade, new plantations of pistachio have been established using the cultivar Siirt (Kaska, 1995), which has relative alternate bearing habit. We analyzed two samples, 'Siirt a' and 'Siirt b', collected from different locations in Turkey. The identity of 'Siirt b' sample could not be verified as 'Siirt'. Since no SSR marker was found to separate the two 'Siirt' cultivars from each other, it was concluded that 'Siirt b' is 'Siirt'. No cultivarspecific alleles were found for the identification of 'Siirt'.

We have developed SSR markers for pistachio with high efficiency for detecting polymorphisms among different pistachio cultivars. We isolated quality DNA from pistachio kernel and shell that was used for DNA fingerprint development. Since we extracted DNA from a portion of a single nut, we can find sample mix-ups. The method can also be used when nuts have been roasted and salted especially by using DNA from the shell. The extraction of DNA from pistachio kernel and shell coupled with the appropriate marker systems developed here, permit analyses and measurement of product trueness to type.

\section{Literature Cited}

Agar, I.T., S. Kafkas, N. Kaska, and A. Sheibani. 1995a. Lipid characteristics of Turkish and Iranian pistachio kernels. Acta Hort. 419: 417-422.

Agar. I.T., N. Kaska, and S. Kafkas. 1995b. Effect of different ecologies on the fat content and fatty acid composition of different Pistacia vera varieties grown in different parts of Turkey. Acta Hort. 419:411-416.

Ahmad, R., D. Struss., and S.M. Southwick. 2003. Development and characterization of microsatellite markers in Citrus. J. Amer. Soc. Hort. Sci. 128:584-590.

Al-Husny, B. 1972. The pistachio (in Arabic). Syria Min. Agr. Agrarian reform, Directorate Agr. Affairs Agr. Ext. Serv. Lflt. 22.

Barone, E., L. Di Marco, F.P. Marra, and M. Sidari. 1993. Isozymes and multivariate analysis to discriminate male and female Sicilian germplasm of pistachio. IX G.R.E.M.P.A. meeting - Pistachio, Agrigento, Italy.

Bender, B. 1975. Farming in prehistory: From hunter gatherer to food producer. John Baker Publ., London.

Butcher,P.A., S. Decroocq, Y. Gray, and G.F. Moran. 2000. Development, inheritance and cross-species amplification of microsatellite markers from Acacia maggium. Theor. Appl. Genet. 101:1282-1290.

Dollo, L. 1993. An isozyme study of Sicilian Pistacia species, varieties, and offspring from artificial pollination. IX G.R.E.M.P.A. meetingPistachio, Agrigento, Italy.

Dyszel, S.M and B.C. Pettit. 1990. Determination of the country of origin of Pistachio nuts by DSC and HPLC. JAOCS. 67:947-951.

Ferguson, L. 1998. The California pistachio industry. Acta Hort. 470: $38-42$.

Fasihi-Harandi, O., B.S. Behboodi., C.A.Mishani and M. Ghaffari. 2001. Chromosome studies and botanical distribution of Iranian pistachio species. PAG IX:P04.

Guilford, P., S. Prakash, J.M. Zhu, E. Rikkerink, S. Gardiner, H. Bassett, and R. Forster. 1997. Microsatellite in Malus $\times$ domestica (apple). Abundance, polymorphism and cultivar identification. Theor. Appl. Genet. 94:249-245.

Hamilton, M.B., E.L. Pincus, A.D Fiore, and R. C. Fleischer. 1999. Universal linker and ligation procedure for construction of genomic DNA 
libraries enriched for microsatellites. Biotechnology. 27:500-507.

Haymer, D.S. 1994. Random amplified polymorphic DNAs and microsatellites: what are they, and can they tell us anything we don't already know? Ann. Ent. Soc. Amer. 87:717-722.

Hormaza, J. I., L. Dollo, and V. S. Polito. 1994. Determination of relatedness and geographical movements of Pistacia vera (Pistachio; Anacardiaceae) germplasm by RAPD analysis. Econ. Bot. 48:349-358.

Karaca, R. and A. Nizamoglu. 1995. Quality characteristics of Turkish and Iranian Pistachio cultivars grown in Gaziantep. Acta Hort. 419: 307-312.

Kaska, N. 1995. Pistachio nut growing in Turkey. Acta Hort. 419: 161-164.

Kijas, J.M.H., J.C.S. Fowler, and M.R. Thomas. 1995. An evaluation of sequence tagged microsatellite site markers for genetic analysis within Citrus and related species. Genome 38:349-355.

Kijas, J.M.H., M.R. Thomas., J.C.S. Fowler, and M.L. Roose 1997. Integration of trinucleotide microsatellites into a linkage map of Citrus. Theor. Appl. Genet. 94:701-706.

Kramer, C. 1982. Village ethnoarchaeology; rural Iran in archaeological. Academic Press, New York.

McCouch, R.S., X. Chen, O. Panaud, S. Temnykh, Y. Xu, Y. G. Cho, N. Huang, T. Ishii, and M. Blair. 1997. Microsatellite marker development, mapping and applications in rice genetics and breeding. Plant
Mol. Biol. 35:89-99.

Nahlawi, N., M.A. Kotob, A. Hadj-Hassan, and I. Haj-Ibrahim. 1985. Effect of modern techniques in growing pistachio tree under arid zone conditions (in Arabic with English summary), Ascad, Ps, P17,40P.

Powell, W., G.C. Machray, and J. Provan. 1996. Polymorphism revealed by simple sequence repeats. Trends Plant Sci. 1:209-245.

Smith, D. and M. Devey. 1994. Occurrence and inheritance of microsatellites in Pinus radiata. Genome 37:977-983.

Swofford, D.L.1999. PAUP: Phylogenetic analysis using parsimony beta test version 4.0 b2. Sinauer Assoc., Sunderland, Mass.

Temnykh, S., G. DeClerck., A. Lukashova., L. Lipovich., S. Cartinhour. and S. McCouch. 2001. Computational and experimental analyses of microsatellites in rice (Oryza sativa L.): Frequency variation, transposon associations, and genetic marker potential. Genome Res. 11:1441-1452.

Thomas, M.R., N.S. Scott, R. Botta, and J.M.H. Kijas. 1998. Sequence tagged site markers in grape vine and citrus. J. Jpn. Soc. for Hort. Sci. 67:1189-1192.

Wang, Z., J.L.Weber, G. Zhong, and S.D. Tanksley. 1994. Survey of plant short tandem DNA repeats. Theor. Appl. Genet. 88:1-6.

Zohary, M. 1952. A morphological study of the genus Pistacia. Palestine J. Bot. 5:187-228.

Zohary, D. and M. Hopf. 1994. Domestication of plants in old word. $2^{\text {nd }}$ ed.. Oxford Univ. Press, Oxford, p. 278. 